\title{
From Sexuality to Eroticism: The Making of the Human Mind
}

\author{
Ferdinand Fellmann'1, Rebecca Walsh ${ }^{2}$ \\ ${ }^{1}$ Department of Philosophy, Chemnitz University of Technology, Chemnitz, Germany \\ ${ }^{2}$ Department of Philosophy, Münster University, Münster, Germany \\ Email: ferdinand.fellmann@phil.tu-chemnitz.de,rebeccawalsh24@yahoo.com
}

Received 27 November 2015; accepted 23 February 2016; published 26 February 2016

Copyright (C) 2016 by authors and Scientific Research Publishing Inc.

This work is licensed under the Creative Commons Attribution International License (CC BY). http://creativecommons.org/licenses/by/4.0/

c) (7) Open Access

\section{Abstract}

This paper proposes that the human mind in its creativity and emotional self-awareness is the result of the evolutionary transition from sexuality to eroticism. Eroticism is arrived at and defined by the high amount of energy displayed in animal sexuality. We propose that the unique human emotional intelligence is due to this "overflow" of mating energy. What from the survival viewpoint looks like an enormous waste of time and energy reveals itself to be an unexpected psychological benefit. The diversion of sexual energy from procreation-a process that results in erotic fantasies-turns intimacy into a source of human self-consciousness. This places different emphasis on the meaning of eroticism and provides a coherent scenario of mental development beyond mere cognitive capacities. Arguments are presented on how erotic imagination, or sexual excitation as an end in itself, promotes the human propensity for explorative curiosity; data from ethology, psychology, sociology, and neuroscience are presented to support these arguments. As philosophical anthropologists, we do not provide new empirical data, but the available results of comparative behavioral research confirm our hypothesis.

\section{Keywords}

Mating Mind, Sexual Arousal, Waste Principle, Emotional Selection, Self-Consciousness

\section{Introduction}

This article investigates how sexuality has shaped the human mind. We use the term "mind" in describing an awareness of a being that possesses properties such as senses, emotions, knowledge, thoughts, etc. With regard to many psychic functions, animal and human minds differ merely in degree and not in kind. But there is one difference that marks the specific nature of humans: self-conception and self-validation. Contrary to self-feeling, 
or the immediate awareness of oneself as an entity separate from others shown by all primates, self-validation implies a complex and is often ambiguous reference to oneself that we consider unique for humans. This existential consciousness may have given rise to reflection on questions as to why the future is not ours to see, or why do people die, and so forth-feelings that we have no reason to attribute to our closest animal relatives living in mere "presentational immediacy". Stated differently, animals react immediately to their environment as the philosopher Whitehead (1927/1985: p. 31) once put it, "with no appeal to the future". Animals show conflicts of behavior that make them delay, hesitate, vacillate in a given situation. But when the situation has passed, they behave and feel unambiguously as usual. Humans, in contrast, transform such experiences into lasting self-doubt and ambivalent feelings such as gallows humor, love-hate, desperation, etc., attitudes that are characteristic for the complexity of the human psyche.

We find this specific mental difference to be the result of eroticism. Eroticism is difficult to capture in a formula (it is a complex phenomenon, such as sexuality) but is a necessary term in the unfolding of the guiding thesis of this article. The current widespread understanding of eroticism is related to sex appeal, usually thought to be a recent aberration of western culture, similar to pornography. Our definition of eroticism differs from this everyday understanding. We define eroticism as a mental disposition combining sensuality and fancy, an emotional blend of nearness and distance, characteristic of human psychodynamics between the sexes. From an ontological point of view, eroticism can be regarded as virtual sexuality, a kind of sexual desire that may even extend to non-sexual objects such as food or fashion. The bringing about of this imaginative state of mind presupposes a concept of psychology different from evolutionary psychology that identifies the erotic with mating strategies. We therefore make a difference of kind between erotic love, on the one hand, and ways of solving mating problems, on the other hand. This difference becomes clear when one looks at a person's subjective experiences in relation to a beloved person. It is at this point that anthropology goes beyond behaviorism and becomes the study of mutual understanding, mind reading, and caring about what others feel and intend.

Our emphasis on sexuality, and not other drives, is due to the extremely intense and largely self-sufficient nature of sexual arousal. In terms of the "survival of the fittest", sexuality seems to involve a huge waste of both time and energy out of proportion to the biological end. From the subjective perspective, however, such seemingly wasteful arousal fosters freedom for spontaneous, unexpected subjective experiences in humans. The human's entire view of their companions and of themselves is changed by eroticism: they are no longer subjected to optimizing reproductive fitness and adaptation. Sexual desire is the source of fantasizing emotional states of excitement in intimacy. In a sense, eroticism "remodels" emotions and motivations, causing them to become more complex and sensitive, e.g., mere expectations become hope, and definite fear becomes angst or existential loneliness, feelings probably unfamiliar to animals.

Modern anthropologists like Diamond (1998) and Miller (2001) argue that, along with upright posture and large brains, humans' unusual sexual behavior was essential for the evolution of Homo sapiens. But the question becomes relevant, how did the transformation of overflowing sexual energy into eroticism actually happen in the Pleistocene? On the evolutionary level, mating strategies evolved according to Darwin's logic of sexual selection, resulting in a reproductive advantage. But as sexual selection works in an equal manner for animals and humans, there must be a special kind of experience to account for the difference. The "front-stage" scenarios accounting for the animal to human transition include the upright gait and liberation of the hands, which are used for tool-making, along with explorative curiosity, symbolic language, and more recently alloparenting. But, as will be elaborated in the following, there seems to be a "back-stage" scenario for the evolution of the human mind as well, one which requires a specific understanding of the molding force of "emotional selection."1 The major methodological goal of this article is to convince biological scientists that the concept of mind requires two ways of seeing: the observer-perspective and the first-person perspective. Both perspectives are complementary and isomorphic in the sense that complex structures of behavior and of emotionality can be put on the map reciprocally. This complementarity generated meaning in the mind's sentiment a million of years before the emergence of verbal language. Our contention is to demonstrate that the erotic is the continuous flow of human sympathetic consciousness that helps to regain the "paradise lost" of animals, but on a higher level. We consider eroticism to make sex relation, despite its inner contradictions, a valid and precious model of trust, faith, and responsibility in the evolution of humans' conscious behavior.

${ }^{1}$ For a complete definition and explanation see our article: Fellmann \& Walsh (2013) Emotional Selection and Human Personality. Biological Theory 8: 64-73; the idea is also defined and summarized in the last section of this paper. 


\section{The Energy of Sexual Arousal}

This section examines the nature and function of sexual arousal in mating behavior. Various models of the process of sexual arousal have been presented since the early 1960s in order to establish the biological bases for love in humans. ${ }^{2}$ It is commonly recognized that sexual arousal is exceptional because it sets free a large amount of energy. In comparison to other needs or drives, there is a notable difference between sexual desire and the sensations of hunger and thirst: while hunger and thirst occur due to certain states of physiological insufficiency, no similar state of physiological deficiency has been revealed to exist in sexuality.

In all mating systems, sexual arousal is an indispensable part of the motivational mechanism effecting physiological and emotional changes that stimulate the whole organism. ${ }^{3}$ This is the case in all species. Take the often cited example of the cichlid fish. With its dance-like movements and splendid display of brilliant colors in pair formation, there is a remarkable intensity of excitation. The female is excited by the male's excitement and insemination ensues. In this case, the biological end of the expenditure of energy is reached: reproduction essential to the survival of the species.

But ethologists, like Konrad Lorenz, have observed for quite some time now that sexual arousal is not merely a successful means to reach an end, namely reproduction. For instance, Lorenz noticed in particular the striking disproportion between the "blaze of excitement" in the courtship state and the indifference with which copulation is performed by many animals. Economically speaking, sexual arousal vastly exceeds what might be necessary to reach the biological end. In other words, the expenditure of energy could be far less to reach the consummatory act of copulation and therefore seems to be a "waste" of energy (Lorenz, 1967: p. 110). The prominent anthropologist Helen Fisher rightly calls Eros "high-energy love for a very special partner" (Fisher, 2004: p. 95).

Analogously, in his Psychology of Sex, Ellis studied such spontaneous manifestations of the sexual impulse not necessary to reach the biological end, which he termed "auto-erotism"-now a widely used term in evolutionary psychology (Ellis, 1906/1936: pp. 161-283, vol. I, part 2). “Auto-erotism” is especially evident in self-stimulation, a widely and readily practiced form of "extended" sexual behavior especially of apes. A further instance of such behavior is evident in the face-to-face copulation practiced by bonobos, which apparently intensifies pleasurable sensations (de Waal, 2005: pp. 92, 96), and it should also be stated that apes engage in erotic interaction for social appeasement.

The archaeologist Dunnell (1999) in his "waste hypothesis" defined a "waste" of energy as any cultural diversion of energy from reproduction. This "waste" of energy is still greater in humans than in most animals. Humans are permanently arousable, whereas most animals experience sexual arousal during a limited period of heat. In terms of the "survival of the fittest", human sex seems to be "a monumental waste of effort", a "huge waste of time and energy" (Diamond, 1998: p. 86, 2006: p. 78). And Geoffrey Miller has also noted the "infinite variety of waste" in human courtship, which is perceived as "romantic" and not pragmatic (Miller, 2001: p. 128). These wasteful displays are much more ubiquitous than was recognized by Darwin, or even by Zahavi (1975) in his handicap hypothesis. Such displays can be found in any kind of sexual interaction (Hawkes, 2002). Huxley (2010: p. 483) states that sexual selection frequently leads to hypertely of no manifest survival value for the species as a whole, whereas Tinbergen (1951: p. 204) suggests that "hypertely may, much more often than is generally believed, concern social releasers rather than functionless structures or 'luxuries'”. Tinbergen finds many ethologists interpret such social releasers as hypertely, when in fact they "have in common that they all have selective value as means of facilitating social cooperation" (ibid., p. 204). In support of the thesis presented in this article, it can likewise be stated that this "wasted energy" of human sex has a value indeed. The surplus energy of sexual arousal seems to have led to the complex emotionality in humans.

In our view we cannot know what animals experience; though their behavior can be observed and reconstructed, we ultimately do not know how they "feel”. Lorenz (1971: pp. 322-337) himself addressed this issue exactly in 1963, when he gave an evasive answer to the question, "[Do] animals undergo subjective experience?" It is generally taken for granted that animals have a subjective experience similar to ours. Yet, what Erlebnis (experience) really means, in view of the fact that nervous functions can also occur without any subjective component, Lorenz is unable to say. He rightly states that the definition of subjective experience touches on the

\footnotetext{
${ }^{2}$ See Toates (2009). An integrative theoretical framework for understanding sexual motivation, arousal, and behavior. Journal of Sex Research 46 (2-3): 168-193.

${ }^{3}$ See Morris's discussion of sexual arousal and physiological changes in The Naked Ape, pp. 34-69.
} 
body-mind problem, which, from the methodological viewpoint of quantifying tests, appears to be unsolvable. The answer to Lorenz's question ultimately remains inconclusive. In a similar vein, Lorenz (1971: p. 324) also addressed the problematic human tendency to transfer our experiences onto other beings with an appearance similar to our own, which he referred to as "evidence of you". Recent research about animal behavior has shown much more similarities of mental states between humans and other species than Lorenz could imagine. But keeping Lorenz's cautions closely in mind, especially the error of anthropomorphism, we believe crucial differences between human and animal subjective experience can still be disclosed.

Understanding the human subjective experience has also proved to be difficult for modern day anthropologists. Though the dynamic integration of the psychological and physical aspects of sexual arousal has been recognized (Chivers, 2005), most quantitative research involves measuring genital arousal alone; such quantitative research has trouble measuring or explaining the human experience of arousal in its psychological form, commonly referred to as "emotional arousal". And evolutionary anthropologists have encountered great difficulties in their efforts to understand the "interior" view, or consciousness of the human mind, especially concerning the enigma of female sexuality (Thornhill, 2008; Dixson, 2009). Moreover, many evolutionary psychologists view sexual arousal in terms of love: as part of a mere mating strategy (Buss, 2003). But such a "strategic" perspective seems to ignore the existential intricacies of eroticism and runs the great danger of missing the meaning of human self-consciousness. For instance, sexual excitement remains an episode in animal life, but a human's sexual experience influences the subsequent emotional development of the individual: a monkey copulates for the first time and merely moves on as if nothing had happened; but a human's first sexual experience can be traumatic, even leading to feelings of shame and guilt. The ancient biblical story of the fall discloses Adam and Eve's loss of innocence and newly acquired self-knowledge after their first sexual experience: they became aware of their own mortality. This example is presented here as a mythical or symbolic form to express the male-female polarity of the human existence.

Sexual arousal can be redirected in different ways; animals are driven by impulses, which they may be able to delay for a short period of time, ${ }^{4}$ whereas humans can transform their drives into motives. They can deliberate their own motives and be judged by others for having them. Creating such a distance from impulses is not merely a matter of the intellect but seems to be highly related to sensuality: humans learn in sexual experience that the expectation of joy is oftentimes more pleasurable than the actual fulfillment. The pleasure experienced in "anticipation" therefore seems to play a key role in uncoupling sexuality from procreation and transforming it into a creative act that is far more than procreative. In this case, it seems arousal as a means has become an end-in-itself, and procreation has become its byproduct. This inversion of means and end serves as leitmotif for the step from sexuality to eroticism in the making of the human mind.

\section{Animal and Human Emotions}

To support our view that sexual arousal is the deepest source of mental creativity, the difference between human and animal emotions must be clarified. Emotions can be categorized as either fast or slow-response sequences. ${ }^{5}$ The fast-response sequence of emotions is triggered by immediate perception and lasts only seconds, while the slow-response sequence of emotions follows from reflective thought, or from thoughts about our thoughts (Goleman, 2005: pp. 334-338). In other words, the fast-response sequence is quick and involves no conscious awareness, whereas the "slow path to emotion" involves intentional thought, or conscious awareness insofar as one can, to a certain extent, choose what to think about. These emotional pathways are often referred to as "basic" and "higher order". Higher order emotions, however, should not be merely equated with the rational mind: reason is not a faculty entirely different from emotion, as transcendental epistemologists assume, but is based on or colored by emotion. Though some higher primates are able to delay gratification, thus showing a certain degree of awareness, this still must be distinguished from human higher order emotions. One example of such a strictly human higher order emotion is shame, which was noted by Darwin (1879/1970) in his pioneering book The Expression of Emotions in Man and Animals.

Independent of the current debate about the nature of emotional expressions-namely whether they are shaped by our common evolutionary history or culturally invented (Barrett, 2011)—we follow Darwin's contention that

${ }^{4}$ See Beran \& Evans (2012) Language-Trained Chimpanzees (Pan troglodytes) Delay Gratification by Choosing Token Exchange over Immediate Reward Consumption. American Journal of Primatology, 74(9): 864-870.

${ }^{5}$ For a general categorization of the emotions, see Ekman's (1992) basic emotion framework. An Argument for Basic Emotions. Cognition and Emotion, 1992, 6 (3/4): 169-200. 
the primeval human must have been highly sensitive to "personal appearance"-namely how his or her own personal appearance was judged by the other sex and that this sensitivity led to the emergence of shame, which is a strictly human social emotion (1871/2004, pp. 328, 363). The existence of shame in humans seems to indicate that there has been a basic shift in mood and mental state. This is especially evident in human sexuality, which is not a mere physiological arousal but a psychological force that can transform the material act of copulation into a spiritual experience.

Darwin has opened a way to understand the behavior patterns behind human mental states. Present-day anthropologists are divided about the coming into existence of human emotions. Whereas de Waal (2011) states in "What is an animal emotion?" that animals in fact have the capacity to "love", in Intimate Behavior Morris (1971) asserts that animals are not able to love but only engage in partnerships. More specifically, he claims that the male monkey "will continue to exist in the loveless world of rivalries and partnerships, of competition and co-operation", while the female monkey will experience love to her child but will "know no such bond with another adult" (ibid., pp. 72-73). He substantiates his claim with observation, in which he finds they engage in very "little courtship or pre-copulatory behavior", and that the sexual encounter lasts merely a few seconds, after which the monkeys "move apart again" (ibid., p. 97). In agreement with Morris, we find the specifically complex nature of human emotionality is revealed in the simultaneous feelings of emotional nearness and distancein erotic love - which will be elucidated in the following.

Animals have emotions, but do they have spiritual values? Konrad Lorenz's teacher Oskar Heinroth always responded to the criticism that he treated animals like machines in the following way: "On the contrary, animals are emotional people with very little ability to reason" (Lorenz, 1971: p. 334). Although Heinroth underestimates the influence of reason, he does correctly distinguish animals as emotional beings that possess only very limited higher emotional capacities. In contrast, the primatologist de Waal (2011)—referencing findings by the neuroscientist Panksepp (2005)—argues that there is no essential difference between animal and human emotions. After observing the sexual inclinations of apes, which include a mixture of aggression and tenderness, he concludes that higher animals are fully aware of their emotions, and human consciousness is therefore no more than an "add-on" to animal mental states. Although de Waal (2011: p. 203) recognizes arousal to be the root of the "tree of emotions", with its good and bad fruits, his picture does not account for the difference between empathy and affection. Only humans can empathize with others for whom they feel no affection at all. This accounts for moral sensitivity and makes consciousness into a state of mind that is more than merely being "aware" of something. Thus, human consciousness reveals itself as an instance of motives lifting up the primary feelings to a particular self-conscious subject with the perplexing paradoxes in his emotional life. ${ }^{6}$

To explain human consciousness as an instance of motives affecting primary feelings and emotions, we refer to two concurring models in psychology. First, there is the older pleasure-arousal theory, which states that emotion intensity and quality is determined by the degree of experienced pleasure of excitement (Reisenzein, 1994). Second, there is the recent belief-desire theory, according to which the experience of the state of excitement depends on the cognitive interpretation or appraisal of the situation (Reisenzein, 2009). These two models of emotionality can be considered as the step from animal to human emotionality. This transition suggests that the structure and function of consciousness consists in transforming sensory feelings into emotional meanings, which are not found in animal self-recognition. Self-consciousness is thus not merely an add-on to animal sensations but the affective core of human sentiments.

The American philosopher Frankfurt (1988) articulates, in a similar vein, the difference between what he terms "first and second order desires". First order desires are directed toward an object, e.g., desires for food, comfort, or sex, while second order desires are vague and need not necessarily be satisfied, such as erotic fantasies. Frankfurt's view of first and second order desires can also be applied to higher order emotions. One can have a good feeling, and yet feel bad afterwards about one's good feeling. The ambiguity is characteristic of our experience of the post-coital state, which fluctuates between satisfaction and deception. This ambiguity may be the result of culturally-formed norms, but it seems to have evolutionary roots in "wasteful" sexual arousal. Arousal is experienced as an urge that needs to be satisfied, yet erotic feelings of pleasure and displeasure are independent from mere urges or desires. In existential consciousness, the quality of desire and pleasure is experienced differently: as hope, depression, angst, etc. To express it in a poetical way: Did any ape ever show in the procreative act the half-sensual smile of human lovers?

As Lorenz cautioned against the human tendency to see other beings as "evidence of you", we are skeptical ${ }^{6}$ See the "Multiple Drafts" model of consciousness in Dennett (1992). 
about the truth of the theory of emotional continuity between animals and humans. There is also evidence of a "not you" which modern primatologists like to forget (Steklis, 2013). Primatologists are correct in claiming that apes identify themselves with their internal states, for they strive to change these states if they feel uncomfortable. Even so, this seems to be a self-awareness that is quite far away from self-understanding, which comprehends a self-image as a product of the freedom of the imagination. The emotional background seems to be the blind spot of consciousness that resists all causal explanation. In our view, human self-cognition is the outcome of the ambiguous emotionality related to sexuality. Consciousness thus represents a higher level of awareness, indicating that the step from animal to human mind is tantamount to a quantum leap.

\section{The Ambivalence of Human Erotic Experience}

The significance of the ambivalent experience of erotic love has moved into focus in modern times. In his famous Sonnet CXXIX about "lust in action", Shakespeare describes the ambivalence of sexual desire, calling it a "waste of shame". And Freud (1904/2000: p. 114) also brought light to this ambivalence in his analysis of the word "lust", which has two meanings: the feeling of tension and the relief from tension in satisfaction. Lust in expectation is often described as being more pleasant than the relief from sexual tension in the consummatory act. The experience of human erotic love can be viewed as an intermediate state of mind with contrasting affective attitudes towards a beloved. In extreme cases, this emotional ambivalence may create psychic problems or even lead to sexual crimes. Though modern evolutionary psychologists do examine sexual conflicts in mating behavior-viewing them as biological regularities that underlie human sexual development (Buss, 2003)—-these are far from being “ambivalent” in psychoanalytic terms.

Humans have lost the unifying characteristic of animal courtship behavior: while animals show in succession tenderness and aggression, humans experience tenderness and aggression in a conflicting way, which creates a state of psychic ambivalence. To prevent the negative consequences of the clash of emotions, human sexual life is bound to culture from the outset. All over the world, sexuality is subjected to various and absurd forms of social constraints. Ethnology in the twentieth century has afforded a vast panorama of sexual approaches, where one sees eroticism combined with love-magic and kinship systems in primitive societies. In his classic, The Sexual Life of Savages (1929), for instance, Malinowski (1968: p. 288) reports the multiple taboos that regulate an erotic approach. And though she never explicitly states that relations between the sexes are ambivalent, Mead (1935) sheds light on the diversity of shared sexuality and free love in tropical cultures. Apart from the myth of the blank slate and the behaviorist theory of learning, Mead's findings confirm the infinite erotic variability that is based on the tendency of human sexuality to run wild. Even falling in love, which used to be dismissed as a recent invention of romantic Europeans, turns out to be a universal trait of human sexuality, which can cause disorder in the social organization (e.g., disrupting arranged political, economic, or diplomatic marriages).

Ambivalence may also be the key to understanding whether animals can "love". It could be stated that animals do not have the capacity to love because animal courtship is always concrete. Animals may exhibit aggressiveness or indifference, but they do not experience hate qualitatively different from aggression (i.e., mental and abstract). In On Aggression Lorenz explains that there is a large amount of latent aggression in genuine love that is covered up by commitment; but if the loving bond is ruptured, "the horrible phenomenon known as hate makes its appearance" (p. 184). As Lorenz correctly states, "there is no love without aggression, but also no hate without love” (ibid.). Lorenz’s thoughts on aggression have been heavily criticized by philosophers dreaming of a paradise-like community of friendly humans. But such critics overlook how modern humans are torn between love with an exclusive partner and extra-pair sex, and that no culture has yet arrived to completely domesticate human emotional ambivalence in sexuality. Though it undoubtedly has negative social consequences, this eternal conflict is also the source of human self-reflection, which connects bodily sensuality with mental sensibility: humans are capable of imagining the sexual act without having to actually enact it. The Cartesian myth of the "Ghost in the Machine" (Ryle, 1949), commonly held by idealistic philosophers, is overcome by what could be called "Love in the Machine".

\section{From a Pro-Social Community to Human Society}

In Sociobiology, Wilson (1975) describes the transition from animal community to human society. The book discusses the well-known antagonism between sex and sociality resulting from conflicting interests of males and females, recognizing it as a crucial problem of social organization. Understanding complex behaviors like altru- 
ism or deceit in view of the pro-social community of non-human primates can help. Recent behavior research has shown that altruism is far more developed in primates than was previously assumed. ${ }^{7}$ Altruism, "primal empathy", or pro-social behavior-helping those in distress without gaining social reward-has also been observed in mammals (Panksepp, 2011), and primates are indeed able to read emotions from the faces of their associates. The primate's mind may be regarded as an "emotional mind" that has its own logic of empathy. Yet the moral meaning of empathy remains unclear. If empathy is defined as putting oneself in another's place, then it can also be used to manipulate the other. Empathy should therefore not be confused with sympathy, and, as Darwin has pointed out, sympathy is not identical to love (Darwin, 2004: pp. 129, 680). Should the drive to alleviate the perceived distress of fellow creatures be compared to human commiseration or pity?

Pro-social behavior among animals-such as helping, consolation, etc.-always refers to a situation in the present with close bodily contact. But because humans are both social animals and individuals, they are able to think and live in abstract social structures-larger than the group of individuals known to each other. Whereas the societal demands in larger units, like fairness and solidarity, are often in conflict with individual and familial attachments, no such "tragic" conflicts of values are observed in animals. Depending on the situation, animals are either friendly or cruel to conspecifics or other species. For instance, a lion that hunts and kills a gazelle does not feel regret. Although a chimpanzee may feel attraction to a particular other, when the attachment is over, they become indifferent to the other. And as mentioned in the last section, there is also no evidence that their attraction transforms into hate after the bond has been ruptured, as it often does for humans. When a young male copulates with a female, the alpha-male may become angry and show sexual envy. But this does not yet constitute jealousy, which is a variant of anger and fear about the presumed infidelity of the beloved. Jealousy is a human universal trait due to the power of the imagination, which, as Darwin long ago noticed, represents "one of the highest prerogatives of man” (2004, p. 95).

Constant sexual receptivity and intense erotic feelings are in many respects culturally destructive and make human society unstable. Although some primates, like bonobos, are able to happily mix the social with the sexual (de Waal, 2006: p. 132), this model is unsuitable for establishing reliable sociality. Even if these primates are envied for their happiness, nobody wants to switch places with them. Culture requires us to separate the sexual and the social domains, as de Waal confirms, but this separation is never really complete, making possible the transformation of sexual motivation into the love of liberty and personal independence. Eroticism affects all human activities (e.g., working, travelling, and playing) because it gives them the character of "maybe", which is then used as a model for human deliberation and decision-making. In other words, eroticism changed fixed behavior patterns into mental activity following the modal logic of possibilia (Church, 1958). Most simply put, an animal encounters the other sex and sees "either/or", whereas a human sees "maybe". The model of the human mind as a mere biological instrument for adaptive solving problems overlooks this way of seeing and is thus inappropriate for understanding the great variability of human social behavior.

There are many forces other than sexuality at the basis of sociality, such as food-supply, shelter from climate, and protection against predators with action-specific arousal. Nevertheless, sexual arousal seems to play a predominant role in the process of socialization because it is highly contagious not only in a given situation but in the long run. Eroticism has broken up the rigid systems of intra-specific behavior and built them up into a human society with its diverse cultural forms. Just as natural exchange, e.g., the exchange of meat for vegetables, was formalized by the introduction of money, sexual desire was formalized by the emergence of erotic display. Thus, sexuality functioning purely as a signal of trust has become the primordial basis of social contracts, which can only be found in "high culture". But how did erotic activity affect the neuronal preconditions, changing the appetitive behavior of primates into sophisticated social rules and norms in human society?

\section{The Brain as the Original Sexual Organ}

As early as 1937, Lorenz (1970: p. 307) used the analogy of a "tap" to explain the discharge of internal "arousal pressure”, which accumulates in periods where stimuli is lacking. Lorenz's idea of an "accumulation” of energy can be seen as a precursor to the early theory of connectionism by the neuropsychologist Donald Hebb, in which brain development is seen as running parallel to the internal production of action-specific excitation. Hebb (1955) claims that a drive has to be activated by an "arousal system" to make organized cortical activity possible. Neuroscience has since explored the Homo sapiens' neocortex, larger than in any other species, as the seat of complex mental capacities. Later, in Behind the Mirror (1978), Lorenz attempts to understand how the human brain

\footnotetext{
${ }^{7}$ See also Warneken et al. (2007) Spontaneous Altruism by Chimpanzees and Young Children. PLoS Biol. Jul; 5(7): e184.
} 
processes information from the outside world using the example of a mirror: the front side of the mirror represents what we experience subjectively in our minds, whereas the obverse of the mirror, which does not reflect, has evolved to gather as much information as is needed to survive (ibid., p. 19).

Yet Lorenz's focus on cognitive faculties caused him to lose sight of the more basic form of experience in emotional life. As the French moralist Marquis de Vauvenargues correctly stated, "[E] motion has taught mankind to reason" (Symons, 1979: p. 45). That emotions provides the scaffolding for social cognition is confirmed by neurophysiological investigations. In Affective Neuroscience, for instance, Panksepp (1998) shows how brain-operating systems organize the fundamental neural sources of human and animal feelings and emotions. And in: The Feeling of What Happens. Body and Emotion in the Making of Consciousness (1999), Damasio (2000) formulates, based on his "somatic maker hypothesis", how emotions and their biological underpinnings are involved in mind-reading and decision-making, thus scientifically validating the concept of mind as a personalized embodiment of the emotions. The overcoming of the mind-body dualism by neuroscience caused the evolutionary psychologist Dunbar (1998) to create the "social brain hypothesis", which states that large brains reflect "the computational demands of the complex social systems that characterize the order", and Miller (2001: pp. 68-98) to claim that the evolution of the human brain is more than a runaway process.

Recent neuroscientific study is concerned with the emotions that feed sexual passion, and offers evidence for similarities between animal and human pleasure cycles in sexual behavior (Georgiadis, Kringelbach, \& Pfaus, 2012). But comparative brain models are problematic since nobody knows if and when animals fantasize. Rats may be able to "get in the moment", and those moments are determined by the incentives of discrete, reward-related cues associated with sexual arousal states. Human sexual passion, on the other hand, has deep reserves and can transcend the moment, often remaining entirely virtual and never acted out in intercourse.

Here, neuronal regulation, or synaptic pruning, which complements Hebbian synaptic changes, may shed light on sophisticated human sexual behavior. The transition from infantile sexuality to adult eroticism fits the changes that can be observed in the cerebral cortex during an individual's development. From the earliest embryonic stage onwards, far more new neurons and synapses are formed than are functionally needed. As a direct response to this overgrowth, a massive synaptic reduction eliminating extra synapses takes place in puberty (Chechik, Meilijson, \& Ruppin, 1999). Because such "complexity decreases over time", the homeostasis of the neural network is maintained (McShea \& Hordijk, 2013). Noteworthy in regard of energy investment is the neuroendocrine model of attachment for pair-bonded animals which are analogous to the behaviors of human couples (Carter, 1998).

The energetic perspective is of great importance for understanding cognition, but it can also be used to understand emotional complexity (Isler \& van Schaik, 2014). Through mediation by the medial prefrontal cortex, the intense sexual excitement radiates into the brain framework as a whole and thus spurs the flow of information about the state of affairs. Adult humans are nearly always sending out signals, some attracting intimacy, others repelling it. Edelman (1989) in his 1989 book, Neural Darwinism—-the Theory of Neuronal Group Selection shows how reentrant signaling between neural groups allows for developmental continuity in response to intimate interaction as the root of self-attention. If the brain were not conditioned in this way, sexual pleasure could never exceed the reward systems that regulate other needs, resulting in a more distributed kind of sensibility of pleasure and pain and at the same time promoting energy trade-offs between the "feel good" chemicals in the brain. A "sweetheart" is thus more thrilling to the pleasure system than sweet chocolate. Therefore, love is not only "in the air" but also in the brain—-the foremost sexual organ.

\section{From Sexual to Emotional Selection}

Having analyzed the unique nature of human subjectivity we now ask: how does the emergence of subjectivity fit to human evolution, especially, what kind of selection is to be taken into account? The multi-factorial process of hominization-e.g., factors such as upright gait, liberation of the hands, tool making, explorative curiosity, and symbolic language; Lorenz (1971: p. 238) mentions central spatial representation, explorative curiosity, and behavioral neoteny - which are usually attributed to natural selection. But none of these preconditions for human evolution are sufficient to account for the emergence of subjectivity taking place on the back-stage of mental evolution. Here sexual selection is closer to emotionality. Due to ideological reasons, Darwinian sexual selection was for a long time neglected by evolutionary research. The revival of the concept of sexual selection in last decades of the $20^{\text {th }}$ century was a great step forward. But due to the predominant focus on sex differences, male competition and female choice. Darwin's theory of sexual selection cannot be used to achieve an under- 
standing of the emotional reciprocity of both lovers (Cluttuon-Brock, 2007). ${ }^{8}$ Following Darwin, evolutionary psychology has been criticized to exaggerate human sex differences (Stewart-Williams \& Thomas, 2013). To be sure, mutual mate choice and parental investment reduce the sex differences which in humans are relatively modest. But the difference to other species is not a quantitative one. However minimal the male-female difference may be, humans are aware of this difference not only in sexual activities but in all social interactions. In addition to recurring behavioral differences there are profound differences in psyche which led us to propose the emotional-selection hypothesis (Fellmann \& Walsh, 2013).

Emotional selection is viewed as a complement to sexual selection or better as its socio-cultural expansion. It goes beyond Darwin's assumption of differential choice for reproductive success. To be sure, selection always works for the survival of the species, but the male-female reciprocity seems to overlap the species' interest. Whereas sexual selection refers to the competition for genetic fitness, emotional selection refers to how pairbonded individuals were motivated to enhance their intersubjective sensibility by the "good feelings" they felt. In this sense, emotional selection is near to affective neural selection (Toronchuk \& Ellis, 2013) insofar as it balances between individual and group selection on the border of the logic of mere biological evolution.

As Bateman (1948) has shown, females are a limiting resource that males compete for in most species. Some males are more successful than others, leading to greater reproductive variance among males rather than females. This difference in variance also works with regard to sexual arousal: some males, though extremely excited by their competition for females, will fail to mate. In biological terms, this is merely a waste of energy. But in terms of subjective experience, this can lead to an increase in erotic attentiveness. Therefore, a strong selective pressure exists for all reproductive losers to become aware of their mental state. In this respect, waste is on the winning side. The "waste principle", as it could be called, extends Bateman's principle to the expression of emotions and desires. Robert Trivers in discussing Bateman's argument of energy investment claims that his theory of parental investment evades the problem of energy because parents and offspring are bound together by instinct (Trivers, 1972). But one should not forget that metabolic energy is not equal to psychic or mental energy in sexual arousal. Emotional selection works through sexual arousability, making lovers feel a kind of mental communion for one another which is not reducible to the energies of the body.

Our concept of emotional selection agrees with C. Owen Lovejoy's widely discussed pair-bonding hypothesis of human origins. For Lovejoy the pair bonds play a major role in the emergence of individual sexual uniqueness (Lovejoy, 2009). But whether early humans were in fact monogamous or polygamous is not decisive here because pair-bonding occurred within polygamous hordes. The important factor is the change of emotionality in a long term pair-bond, as casual as it might have been in the beginning. In erotic love, a "partner" becomes a subject-an irreplaceable person (Morris, 2005: p. 73). Research on monogamous and cooperatively breeding primates has documented, that humans are not the only species that show emotional attachment to the partner analogous shown by human lovers. One may question whether they do have the same erotic sense as humans. Our answer is "no" because erotic sense goes beyond the actual bond and extends over all intimate relations. This sense of possibility is the beginning of human intersubjectivity in which individuals are united by their personal way of loving and not by the feeling of belonging to a community (Davis, 1973: p. 169). Thus, the concept of emotional selection goes hand-in-hand with eroticism, a feeling founded in sexuality but at the same time transcending the evolutionary goal of sexuality. Emotional selection and eroticism are both motivational factors usually underrated in the evolution of the human mind.

\section{The Language of the Emotions}

To elucidate our concept of emotional selection, it may be compared with Robin Dunbar's acclaimed "social gossip hypothesis" (Dunbar, 2014: p. 264; Buss, 2005: p. 395). Dunbar suggests that the human brain rapidly expanded around two million years ago to cope with the large numbers of social relationships in increasing primate groups. The development of sociality has its cost. In small groups whose members know each other, the social interaction is functionally ordered. Living in large groups creates stress (Gamble, Gowlett, \& Dunbar, 2014: p. 39). To deal with the stress, hominids invented language, especially gossip, as an extension of grooming behavior. Gossip helped to keep track of a larger number of social relationships than could be cared for by direct interaction. The social gossip hypothesis thus appears to be a promising way to explain the world of partnerships, competition, and cooperation in large groups. ${ }^{9}$

${ }^{8}$ Regarding sexual selection Darwin occasionally mentions that in the couple females as well as males select partners—a "double process of selection”- but he did not work out this idea (2004, p. 261). 
But the human bond is not a mere partnership of exchanging favors. Humans strive for long-term loving bonds founded on intimacy and privacy. Such bonds do in fact make lovers feel good and secure; recent studies have shown that positive social relationships reduce stress responses (Sachser, Dürschlag, \& Hirzel, 1998) and that the presence of a social companion may moderate the hypothalamic-pituitary-adrenocortical (HPA) system's response to stressors, thus promoting health and social cohesion (Hennesy, Kaiser, \& Sachser, 2009). On the other hand intimate relations between the sexes also generate stresses different from those experienced in group-living (Davis, 1973: p. 245). The latter can be reduced or avoided by simply going away from the group, whereas the other is always mentally present in the loving pair. The specific stress of intimacy felt towards one individual person - the simultaneousness experience of nearness and distance-is unknown to the social behavior of primates, which is why we suggest that the formation of the long-term pair bond may have led humans to an intensification of the emotional mind. Paradoxically, this is confirmed by Dunbar's statement that monogamy is an evolutionary dead end, "that there is no route out of monogamy" (Dunbar, 2014: p. 51; Gamble, Gowlett, \& Dunbar, 2014: p. 68). The pair-bonding hypothesis indicates indeed the end of biological evolution and the beginning of cultural co-evolution.

The language of the emotions therefore seems to be more than gossip as Dunbar understands it. While gossip signals cooperation with an unknown member of the community, akin to the "animal language" of primates living in social systems with dominance relationships, lovers invent a personal language of understanding full of metaphors mainly taken from the mother-infant relation ("baby", "sweetheart", etc.). This is the beginning of inter subjective communication described by existential philosophers like Martin Heidegger in Being and Time. ${ }^{10}$ The existential language of the emotions of a mated pair presupposes much more than the forms of social cognition known as "theory of mind" or "mentalizing". Lacking intimate emotions, Dunbar's "gossip" remains a substitute for functional social bonding, which is certainly not sufficient to account for the emergence of the individual mind.

In respect to developed human societies where monogamy is the norm, the erotic displays of women have reached the same level as the aggressive sexual need of males. Both men and women have therefore been made winners by the surplus of sexual energy. The double form of selection does not cancel the fact "that a basic sex difference exists in the psychology of sexual arousal” (Symons, 1979: p. 172). Human culture has overcome sexual dimorphism and has established the erotic as an intermediate state between sexuality and romantic love. In sexual relations, humans are both aggressive and charming, which is reinforced by erotic fantasizing (Georgiadis, Kringelbach, \& Pfaus, 2012). Thus, erotic stimuli, real or ideal, have become permanent enhancers of the emotional and cognitive development of the mating mind. The transformation of sexuality into erotic love, far from being a sign of hypertrophic degeneration, is to be referred to as the root of human sense and sensibility.

\section{Conclusion}

Traditional models of man involve the dualism of body and mind, of emotionality and intelligence. Our aim is to overcome this dualism by an evolutionary perspective. Relying on the results of comparative behavioral research, we reach the conclusion that in the process of hominization the cognitive approach needs the complement of emotional development. Emotional development is enhanced by mutual understanding in intimate relations. In a long-term bond, humans discover how to navigate feelings of closeness and distance, resulting in the acquisition of the sense of personal responsibility. The arousal effect of intimacy transforms sexual needs into erotic representations, and eroticism, therefore, is considered to be the source of the making of the mind. Eroticism, or the high-energy love of Eros has shaped the human psyche; it is more than having sex for fun, since it is a mental disposition to become aware of tenderness between the sexes. Many mammals lead a completely asexual life outside their short heat period; normally they do not live "with" the other sex. For humans, in contrast, the other sex is present at virtually all times, as erotic fantasies always remain. Humans are also able to live in an "intimate distance" with the other, e.g., having sexual relations yet unwilling to live together or vice versa.

Modern primatologists attempt to explain pro-social behavior, and the existence of sympathy or empathy, through the lens of a "natural normativity". Moral norms are considered as the outcome of strategies regarding planning and decision-making in social interaction. These theories fail to recognize the difference between mere functional analogues of ethical behavior in social animals and the unique feeling of personal responsibility in

${ }^{9}$ Miller followed Dunbar's "gossip-as-grooming theory", but transformed it into "gossip-as-courtship theory" by introducing the mating process (Miller, 2001: p. 366).

${ }^{10}$ See Heidegger's discussion of idle talk in Being and Time, § 35. 
humans. We, on our part, conclude that human moral sense is not primarily derived from social welfare, but from emotionality in personal relations with our fellow creatures. Human moral behavior cannot not be reduced to a mere set of survival strategies; a positive evaluation as an end in itself distinguishes humans' self-validation from the acts of social boasting displayed by non-human primates.

We suggest that the difference between the primate individual and the personal self of Homo sapiens lies in the latter's ambiguous emotionality. As neurobiologists have shown, love and hate are intricately connected in the human brain. The coexistence of such complex, abstract, and oppositional emotions enables humans to transcend the primary self-feeling of our closest living relatives. The increased plasticity, or flexibility, of the human mind is recognized by sociobiologists who marvel at how behavior patterns differed greatly even in the simplest societies. In our view, the cultural malleability is the outcome of eroticism that has changed the whole setting of subjective experience. It has caused humans to become "eccentric beings", individuals who are free to reinvent themselves and form identities that represent someone other than who they biologically are. These qualitative shifts in self-image and self-reference lead to what philosophers of mind have called the "anthropological question": "Who am I?"- - question probably no animal ever asked. If we want to understand what is essential in human existence, we are confronted with protean sexuality as the "stuff" our mind is made of. Thus, eroticism is pivotal to explaining what it is to be a human being.

\section{References}

Barrett, L. F. (2011). Was Darwin Wrong about Emotional Expressions? Current Directions in Psychological Science, 20, 400-406. http://dx.doi.org/10.1177/0963721411429125

Beran, M. J., \& Evans, T. A. (2012). Language-Trained Chimpanzees (Pan Troglodytes) Delay Gratification by Choosing Token Exchange over Immediate Reward Consumption. American Journal Primatology, 74, 864-870. http://dx.doi.org/10.1002/ajp.22042

Bateman, A. J. (1948). Intrasexual Selection in Drosophila. Heredety, 2, 249-368.

Buss, D. M. (2003). The Evolution of Desire. Strategies of Human Mating. New York: Basic Books.

Buss, D. M. (2005). The Handbook of Evolutionary Psychology. New York, NJ: John Wiley \& Sons.

Carter, C. S. (1998). Neuroendocrine Perspectives on Social Attachment and Love. Psychoneuroendocrinology, $23,779-818$. http://dx.doi.org/10.1016/S0306-4530(98)00055-9

Chechik, G., Meilijson, I., \& Ruppin, E. (1999). Neuronal Regulation: A Mechanism for Synaptic Pruning during Brain Maturation. Neural Computation, 11, 2151-2170. http://dx.doi.org/10.1162/089976699300016089

Chivers, M. L. (2005). A Brief Review and Discussion of Sex Differences in the Specificity of Sexual Arousal. Sexual and Relationship Therapy, 20, 377-390. http://dx.doi.org/10.1080/14681990500238802

Church, A. (1958). Ontological Commitment. Journal of Philsophy, 55, 1008-1014. http://dx.doi.org/10.2307/2021909

Cluttuon-Brock, T. H. (2007). Sexual Selection in Males and Females. Science, 318, 1882-1885. http://dx.doi.org/10.1126/science.1133311

Damasio, A. R. (2000). The Feeling of What Happens: Body and Emotions in the Making of Consciousness. New York: Mariner Books.

Darwin, C. (1871/2004). The Descent of Man, and Selection in Relation to Sex. London: Penguin Classics.

Darwin, C. (1879/1970). The Expression of the Emotions in Man and Animals. Chicago, IL: UCP.

Dennett, D. C. (1992). Consciousness Explained. London: Penguin Press.

De Waal, F. B. M. (2005). The Empathic Ape. New Scientist, October 8, 52-54.

De Waal, F. B. M. (2006). Our Inner Ape. New York: Riverhead Books.

De Waal, F. B. M. (2011). What Is an Animal Emotion? Annals of the New York Academy of Sciences, 1224, 191-206. http://dx.doi.org/10.1111/j.1749-6632.2010.05912.x

Davis, M. S. (1973). Intimate Relations. New York: The Free Press.

Diamond, J. (1998). Why Is Sex Fun? The Evolution of Human Sexuality. London: Phoenix.

Diamond, J. (2006). The Third Chimpanzee: The Evolution and Future of the Human Animal. New York: Harper Perennial.

Dixson, A. F. (2009). Sexual Selection and the Origins of Human Mating Systems. New York: Oxford University Press.

Dunbar, R. (1998). The Social Brain Hypothesis. Evolutionary Anthropology: Issues, News, and Reviews, 6, 178-190. http://dx.doi.org/10.1002/(SICI)1520-6505(1998)6:5<178::AID-EVAN5>3.0.CO;2-8

Dunbar, R. (2014). Human Evolution. London: Penguin Books. 
Dunnell, R. C. (1999). The Concept of Waste in an Evolutionary Archaeology. Journal of Anthropological Archaeology, 18, 243-250. http://dx.doi.org/10.1006/jaar.1999.0341

Edelman, G. M. (1989). Neural Darwinism: The Theory of Group Neuronal Selection. Oxford: Oxford University Press.

Ekman, P. (1992). An Argument for Basic Emotions. Cognition and Emotion, 6, 169-200. http://dx.doi.org/10.1080/02699939208411068

Ellis, H. (1906/1936). Studies in the Psychology of Sex (Vol. I/II). New York: Random House.

Fellmann, F., \& Walsh, R. (2013). Emotional Selection and Human Personality. Biological Theory, 8, 64-73. http://dx.doi.org/10.1007/s13752-013-0093-3

Fisher, H. (2004). Why We Love: The Nature and Chemistry of Romantic Love. New York: St. Martin’s Griffin.

Frankfurt, H. (1988). The Importance of What We Care about: Philosophical Essays. Cambridge: Cambridge University Press. http://dx.doi.org/10.1017/CBO9780511818172

Freud, S. (1904/2000). Three Essays on the Theory of Sexuality. New York: Basic Books.

Gamble, C., Gowlett, J., \& Dunbar, R. (2014). Thinking Big: How the Evolution of Social Life Shaped the Human Mind. London: Thames \& Hudson.

Georgiadis, J. R., Kringelbach, M. L., \& Pfaus, J. G. (2012). Sex for Fun: Bringing Together Human and Animal Neurobiology. Nature Reviews Urology, 9, 486-498. http://dx.doi.org/10.1038/nrurol.2012.151

Goleman, D. (2005). Emotional Intelligence: Why It Can Matter More Than IQ. New York: Bantam Books.

Hawkes, K., \& Bird, R. B. (2002). Showing Off, Handicap Signaling, and the Evolution of Men’s Work. Evolutionary Anthropology, 11, 58-67. http://dx.doi.org/10.1002/evan.20005

Hebb, D. (1955). Drives and the C.N.S. (Conceptual Nervous System). Psychological Review, 62, 243-254. http://dx.doi.org/10.1037/h0041823

Hennesy, M. B., Kaiser, S., \& Sachser, N. (2009). Social Buffering of the Stress Response: Diversity, Mechanisms, and Functions. Frontiers in Neuroendocrinology, 30, 470-482. http://dx.doi.org/10.1016/j.yfrne.2009.06.001

Huxley, J. (1942/2010). Evolution: The Modern Synthesis. Cambridge, MA: MIT Press.

Isler, K., \& van Schaik, C. (2014). How Humans Evolved Large Brains: Comparative Evidence. Evolutionary Anthropology, 23, 65-75. http://dx.doi.org/10.1002/evan.21403

Lorenz, K. (1970/1971). Studies in Human Behaviour, Volume I and II. London: Methuen.

Lorenz, K. (1967). On Aggression: A University Paperback. London: Methuen.

Lorenz, K. (1978). Behind the Mirror: A Search for a Natural History of Human Knowledge. New York: A Harvest Book.

Lovejoy, O. (2009). Reexamining Human Origins in Light of Ardipithecus ramidus. Science, 74, e1-e8.

http://dx.doi.org/10.1126/science.1175834

Malinowski, B. (1929/1968). The Sexual Life of Savages in North-Western Melanesia. London: Routledge \& Kegan Paul.

McShea, D. W., \& Hordijk, W. (2013). Complexity by Abstraction. Evolutionary Biology, 40, 504-520.

http://dx.doi.org/10.1007/s11692-013-9227-6

Mead, M. (1935). Sex and Temperament in Three Primitive Societies. New York: William Morrow.

Miller, G. (2001). The Mating Mind: How Sexual Choice Shaped the Evolution of Human Nature. London: Vintage.

Morris, D. (1971). Intimate Behavior. London: Jonathan Cape.

Panksepp, J. (1998). Affective Neuroscience: The Foundation of Human and Animal Emotions. New York and Oxford: OUP.

Panksepp, J. (2005). Affective Consciousness: Core Emotional Feelings in Animals and Humans. Consciousness and Cognition, 14, 30-80. http://dx.doi.org/10.1016/j.concog.2004.10.004

Panksepp, J. (2011). Empathy and the Laws of Affect. Science, 334, 1358-1359. http://dx.doi.org/10.1126/science.1216480

Reisenzein, R. (1994). Pleasure-Arousal Theory and the Intensity of Emotions. Journal of Personality and Social Psychology, 67, 525-539. http://dx.doi.org/10.1037/0022-3514.67.3.525

Reisenzein, R. (2009). Emotional Experience in the Computational Belief-Desire Theory of Emotion. Emotion Review, 1, 214-222. http://dx.doi.org/10.1177/1754073909103589

Ryle, G. (1949/1963). The Concept of Mind. Harmondsworth: Peregrine Books.

Sachser, N., Dürschlag, M., \& Hirzel, D. (1998). Social Relationships and the Management of Stress. Psychoneuroendocrinology, 23, 891-904. http://dx.doi.org/10.1016/S0306-4530(98)00059-6

Steklis, H. D., \& Lane, R. D. (2013). The Unique Human Capacity for Emotional Awareness. In S. Watanabe, \& S. Kuczaj (Eds.), Emotions of Animals and Humans: Comparative Perspectives (pp. 165-179). New York: Springer Science \& 
Business Media.

Stewart-Williams, S., \& Thomas, S. G. (2013). The Ape That Thought It Was a Peacock: Does Evolutionary Psychology Exaggerate Human Sex Differences? Psychological Inquiry, 24, 137-168. http://dx.doi.org/10.1080/1047840X.2013.804899

Symons, D. (1979). The Evolution of Human Sexuality. New York: Oxford University Press.

Toates, F. (2009). An Integrative Theoretical Framework for Understanding Sexual Motivation, Arousal, and Behavior. Journal of Sex Research, 46, 168-193. http://dx.doi.org/10.1080/00224490902747768

Thornhill, R., \& Gangestad, S. W. (2008). The Evolutionary Biology of Human Female Sexuality. New York: Oxford University Press.

Tinbergen, N. (1951). The Study of Instinct. Oxford: Clarendon Press.

Toronchuk, J. A., \& Ellis, G. F. R. (2013). Affective Neuronal Selection: The Nature of the Primordial Emotion Systems. Frontiers in Psychology, 3, 589. http://dx.doi.org/10.3389/fpsyg.2012.00589

Trivers, R. L. (1972). Parental Investment and Sexual Selection. In E. Campbell (Ed.), Sexual Selection and the Descent of Man (pp. 136-179). Chicago, IL: Aldine.

Whitehead, A. N. (1927/1985). Symbolism: Its Meaning and Effect. New York: Fordham University Press.

Wilson, E. O. (1975). Sociobiology: The Abridged Edition: The New Synthesis. Cambridge, MA: Harvard University Press.

Zahavi, A. (1975). Mate Selection-A Selection for a Handicap. Journal of Theoretical Biology, 53, 205-214. http://dx.doi.org/10.1016/0022-5193(75)90111-3 


\section{Further References (Not Cited in the Article)}

Barrett, L. F., \& Fossum, T. (2001). Mental Representations of Affect Knowledge. Cognition \& Emotion, 15, 333-363. http://dx.doi.org/10.1080/02699930125711

Bekoff, M. (2000). Animal Emotions: Exploring Passionate Natures. BioScience, 50, 861-870. http://dx.doi.org/10.1641/0006-3568(2000)050[0861:AEEPN]2.0.CO;2

Bird, A. (2007). Perception of Epigenetics. Nature, 447, 396-398. http://dx.doi.org/10.1038/nature05913

Blaffer Hrdy, S. (2009). Mothers and Others: The Evolutionary Origins of Mutual Understanding. Cambridge, MA: The Belknap Press of Harvard University Press.

Damasio, A. (2006). Descartes’ Error: Emotion, Reason, and the Human Brain. London: Vintage Books.

Dawkins, R. (2006). The Blind Watchmaker. London: Penguin Books.

Ellis, G. F. R., \& Toronchuk, J. A. (2005). Neural Development: Affective and Immune System Influences. In N. Newton, \& G. F. R. Ellis (Eds.), Consciousness and Emotion: Agency, Conscious Choice and Selective Perception (pp. 81-119). Philadelphia, PA: John Benjamins Publishing. http://dx.doi.org/10.1075/ceb.1.06ell

Evans, D. T. (1993). Sexual Citizenship: The Material Construction of Sexualities. New York: Routledge. http://dx.doi.org/10.4324/9780203412398

Everaerd, W., Both, S., \& Laan, E. (2006). The Experience of Sexual Emotions. Annual Review of Sex Research, 17, 183199.

Fisher, H. (1994). Anatomy of Love: A Natural History of Mating, Marriage and Why We Stray. New York: Ballantine Books.

Fisher, H. (1998). Lust, Attraction and Attachment in Mammalian Reproduction. Human Nature, 9, 23-52. http://dx.doi.org/10.1007/s12110-998-1010-5

Georgiadis, J. R., \& Kringelbach, M. L. (2012). The Human Sexual Response Cycle: Brain Imaging Evidence Linking Sex to Other Pleasures. Progress in Neurobiology, 98, 49-81. http://dx.doi.org/10.1016/j.pneurobio.2012.05.004

Kappeler, P. M., \& van Schaik, C. (Eds.) (2012). Sexual Selection in Primates: New and Comparative. Cambridge: Cambridge University Press.

King, B. J. (2013). How Animals Grieve. Chicago, IL: The University of Chicago Press. http://dx.doi.org/10.7208/chicago/9780226043722.001.0001

Lomanowska, A. M., \& Guitton, M. J. (2012). Virtually Naked: Virtual Environment Reveals Sex-Dependent Nature of Skin Disclosure. PLoS ONE, 7, e51921. http://dx.doi.org/10.1371/journal.pone.0051921

Neubert, F. X. et al. (2014). Comparison of Human Ventral Frontal Cortex Areas for Cognitive Control and Language with Areas in Monkey Frontal Cortex. Neuron, 81, 700-713. http://dx.doi.org/10.1016/j.neuron.2013.11.012

Smith, J. M. (1988). Did Darwin Get It Right? Essays on Games, Sex and Evolution. London: Penguin Books.

Snowdon, C. (2004). Sexual Selection and Communication. In P. M. Kappeler, \& C. P. Van Schaik (Eds.), Sexual Selection in Primates (pp. 57-70). Cambridge: Cambridge University Press. http://dx.doi.org/10.1017/CBO9780511542459.006

Sterelny, K. (2012). The Evolved Apprentice. Cambridge, MA: MIT Press. http://dx.doi.org/10.7551/mitpress/9780262016797.001.0001 